
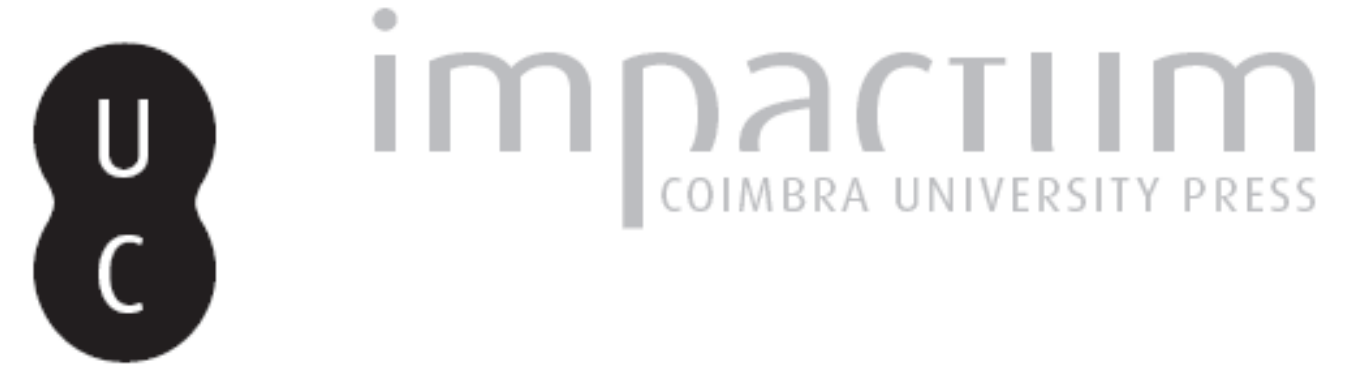

Conceitos sem fronteiras: Frege e Wittgenstein

Autor(es): $\quad$ Soares, Maria Luísa Couto Publicado por: Faculdade de Letras da Universidade de Coimbra, Instituto de Estudos
Filosóficos

URL

persistente:

URI:http://hdl.handle.net/10316.2/35605

DOI:

DOI:http://dx.doi.org/10.14195/0872-0851_45_9

Accessed : $\quad$ 26-Apr-2023 10:52:45

A navegação consulta e descarregamento dos títulos inseridos nas Bibliotecas Digitais UC Digitalis, UC Pombalina e UC Impactum, pressupõem a aceitação plena e sem reservas dos Termos e Condições de Uso destas Bibliotecas Digitais, disponíveis em https://digitalis.uc.pt/pt-pt/termos.

Conforme exposto nos referidos Termos e Condições de Uso, o descarregamento de títulos de acesso restrito requer uma licença válida de autorização devendo o utilizador aceder ao(s) documento(s) a partir de um endereço de IP da instituição detentora da supramencionada licença.

Ao utilizador é apenas permitido o descarregamento para uso pessoal, pelo que o emprego do(s) título(s) descarregado(s) para outro fim, designadamente comercial, carece de autorização do respetivo autor ou editor da obra.

Na medida em que todas as obras da UC Digitalis se encontram protegidas pelo Código do Direito de Autor e Direitos Conexos e demais legislação aplicável, toda a cópia, parcial ou total, deste documento, nos casos em que é legalmente admitida, deverá conter ou fazer-se acompanhar por este aviso.

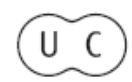




\section{REVISTA FILOSÓFICA DE COIMBRA}

vol. 23 - número 45 - março 2014

vol. 23 - número 45 - março 2014 Fundação Eng. António de Almeida

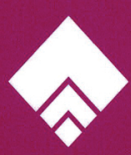




\title{
CONCEITOS SEM FRONTEIRAS: FREGE E WITTGENSTEIN
}

\author{
MARIA LUÍSA COUTO SOARES*
}

Times change and forms and their meanings alter. Thus new poems are necessary. Their forms must be discovered in the living language of their day, or old forms, embodying exploded concepts, will tyrannize over the imagination.

Charles Williams

Les mots ne changent pas tant de signification pendant des siècles que pour nous les noms dans l'espace de quelques années.

Marcel Proust

Resumo: A exigência de contornos nítidos constitui para Frege o critério do reconhecimento de um conceito que não admite nenhum tipo de vagueza. Wittgenstein rejeita este requisito de Frege: a vagueza e a ausência de fronteiras nítidas não constituem obstáculo para a compreensão da linguagem. Esta divergência entre Frege e Wittgenstein está rodeada de muitas afinidades: as diferenças radicam mais no âmbito da linguagem no qual se centra cada um dos pensadores. $\mathrm{O}$ carácter vago da linguagem é tolerado por Frege no seu uso corrente, não estritamente lógico e científico. Para Wittgenstein, a vagueza é constitutiva da própria linguagem humana, enquanto conjunto infinito de jogos que não se deixa aprisionar por nenhum sistema de regras. Exceder sempre as regras é precisamente o sinal da impossibilidade de um domínio exaustivo e completo do uso da nossa linguagem.

Palavras-chave: conceito - lógica - linguagem corrente - uso - regras - vagueza.

Abstract: The requirement of sharp boundaries is for Frege the criterion of recognition of a concept that does not admit any kind of vagueness. Wittgenstein rejects this requirement of Frege: vagueness and the lack of sharp boundaries are not an obstacle for the understanding of language. This divergence between Frege and

* Faculdade de Ciências Sociais e Humanas da Universidade Nova de Lisboa. 
Wittgenstein is surrounded by many affinities: the differences lie above all in the field of language in which each of the thinkers centres his attention. The vagueness of language is tolerated by Frege in its ordinary use, not strictly logical and scientific. For Wittgenstein, vagueness is constitutive of human language itself as an infinite set of games that is not held captive by any system of rules. To exceed the rules is exactly the sign of the impossibility of an exhaustive and complete command of the use of our language.

Keywords: concept - logic - ordinary language - use - rules - vagueness.

Este ensaio apresenta um confronto entre as teorias do conceito de Frege e de Wittgenstein. A exigência de conceitos com contornos nítidos constitui para Frege o critério para reconhecer um conceito. Este requisito é rejeitado por Wittgenstein, para quem a vagueza e a falta de exatidão da nossa linguagem corrente não constitui obstáculo para a sua compreensão.

A discussão entre Frege e Wittgenstein fará ver que a aparente oposição entre ambos está rodeada de muitas afinidades. Frege impõe este requisito à linguagem lógica, e reconhece a vagueza da linguagem corrente, que considera imperfeita e imprópria para exprimir raciocínios logicamente correctos. Wittgenstein libertara-se dessa "falsa prisão" e dedica-se à tarefa de elucidar a gramática com o fito de fazer com que compreendamos o que dizemos. Nesta investigação gramatical encontramos afinidades com Frege, que pretendemos mostrar.

No Prefácio do Tractatus, Wittgenstein exprime claramente a sua dívida intelectual em relação a Frege: "Quero apenas mencionar que os meus pensamentos foram em grande parte sugeridos pelas grandes obras de Frege e pelos trabalhos do meu amigo, o senhor Bertrand Russell".

Quanto à amizade com Russell sabemos o que se passou mais tarde, no período pós-tractariano. Quanto a Frege, cuja influência é bem visível no Tractatus, essa dívida permanece, mesmo depois da rejeição de algumas das teses fundamentais desta primeira obra. Frege continuará a ser um interlocutor de Wittgenstein nas discussões e confrontos de muitos aspectos que entram em conflito com o pensamento fregeano. Esse mesmo conflito revela também, ainda que de outro modo, a relevância do pensamento de Frege nas análises gramaticais de Wittgenstein. É como um contraste que torna ainda mais nítidas tanto as teses de Frege como as discussões de Wittgenstein. Divergir de outro pensador, ter em conta as suas opiniões para as discutir, mostra que este não lhe é indiferente, pelo contrário, que o interpela e o convoca. 


\section{Diálogos e desencontros}

As frequentes referências a Frege em todos os escritos de Wittgenstein, mostram que este conhecia bem e tinha presente a sua obra. E alguma vez, Wittgenstein terá exprimido o desejo de ter sido capaz de escrever como Frege, o que revela bem, apesar das profundas divergências, a admiração intelectual que sempre sentiu por ele.

Um dos aspectos mais controversos, são precisamente as noções de sentido, significação, do uso como factor de sentido, do ideal de linguagem formal, logicamente perfeita que ambos perfilharam a princípio, mas que depois seguiu um rumo completamente distinto, em cada um. É neste contexto que se insere o tema e o problema do conceito: conceito com contornos perfeitamente delineados, é uma exigência da "sublimação da lógica"; a linguagem corrente é vaga, ambígua, emprega termos conceptuais com "contornos esfumados".

Seria fácil pensar simplesmente que Frege mantém o seu ideal de linguagem lógica, formalmente perfeita, enquanto Wittgenstein se "conforma" com a impossibilidade de uma fixação do significado, de evitar a vagueza da nossa linguagem. De facto, julgo que o problema é bem mais complexo. A exigência fregeana de conceitos com contornos nítidos, tem sido objecto de diversas interpretações, algumas que se complementam, outras que divergem entre si. Gary Kemp ${ }^{1}$ infere mesmo do requisito fregeano impasses lógicos insuperáveis. Muito pouco do que pensamos ou dizemos é necessariamente verdadeiro ou falso, considera Kemp. O primeiro exemplo que aponta é o das sorites ('z é um montão') onde o predicado não é nem verdadeiro nem falso para certos objectos aos quais pode ser atribuído. Frege considera pura e simplesmente que "montão" não é um conceito. O segundo exemplo evocado é o caso de muitos dos sinais de funções que só são aplicáveis num subconjunto do universo de objectos em geral. "Esfomeado" tem uma extensão determinada, um subconjunto do universo dos objectos, nomeadamente seres vivos, homens e animais. Portanto, "O número três está esfomeado" é falso, o que

1 Cf Kemp 1996: “[The sharpness requirement] ... is simply one of the laws of truth - that for any concept and any object, either the object falls under the concept, or it falls under its contradictory. A non-sharp concept-sign lacks denotation. [...] The trouble is obvious [...] the implication is that precious little of what we actually think and say is true or false. There are two sorts of cases. First, some expressions, such as ' $\mathrm{z}$ is a heap', have indefinitely bounded extensions, and are thus neither true nor false of certain objects [...] Second, most function-signs seem significantly applicable only within some proper subset of the universe of objects in general [...] For instance, 'The number three is hungry' is false rather than nonsense, and hence that it is true that the number three is not hungry. [...] So the conjunction of Frege's estimate of logic with this logical theory appears not to allow room for either the truth or falsity of ordinary statements." 
implicaria, segundo o requisito de Frege que "O número três não está esfomeado" é verdadeiro.

Que Frege não tenha visto estas dificuldades parece pouco provável. Kemp afirma que Frege não as viu. Certamente que as viu, mas descartou-as sem hesitar: estes argumentos não colhem, porque não têm nada a ver com o que Frege entende por "conceito". Na sua perspectiva, "montão" não é um conceito e "esfomeado" se é um conceito, tem contornos nítidos que o delimitam e só têm sentido as proposições que respeitarem esses contornos. Não é o caso de "número", que não é subsumido pelo conceito de esfomeado, portanto a proposição é simplesmente sem sentido.

Além disso, Frege insistiu sempre na irredutibilidade dos conceitos aos objetos: compreender um conceito, como por exemplo "é humano" não pressupõe familiaridade com os objectos, neste caso todos os homens e mulheres em particular. Os conceitos não são o mero resultado de agregar objetos explícitos ou encontrar traços comuns. Isto responde, em parte ao caso de predicados como "montão" que não é senão um agregado indefinido de objectos particulares com características comuns. A existência dos conceitos independentemente dos objetos tem como corolário a subsunção como a relação lógica fundamental; mas a subsunção de um objecto sob um conceito não é algo de completamente explícito, como seria se a relação conceito/objecto fosse assimilável à relação do todo com a parte. Nesta relação de uma parte com o todo, o todo pode reduzir-se às suas partes. Frege considera que construir na base desta relação "é intuitivamente muito claro e indubitável; mas infelizmente não é lógico".

Wittgenstein não se limita a aceitar pacificamente as dificuldades de compreender e explicar o significado de muitos dos termos conceptuais que empregamos usualmente. E, rejeitando uma perspectiva "essencialista" das expressões conceptuais, multiplica-se em formas de aproximação do seu significado, recorrendo a explicações, a exemplos, a imagens, a metáforas... que não chegarão nunca a permitir uma definição. A possibilidade de excluir qualquer imprecisão, vagueza dos termos conceptuais e de toda a nossa linguagem quotidiana é, para Wittgenstein, um ideal remoto, ou melhor uma miragem que só nos confunde e ilude.

Não é fácil fazer-se uma ideia desta vagueza da linguagem, que seja adequada. Ela joga em torno das palavras como o ar em torno das coisas. Ela é a luz do crepúsculo na qual se banham a maior parte das significações das palavras. Para termos diante dos olhos este factor invisível e, no entanto, presente em toda a parte, gostaríamos de nos esgotar em imagens e metáforas (Gleichnise). Que fixemos pelo menos uma. ${ }^{2}$

\section{D, 139.}


A atitude de Wittgenstein já nos anos 30, é flexível, de aceitação da imprecisão, da vagueza da linguagem, deixando-a ser como é, renunciando a submetê-la a um sistema de regras completo, exaustivo. É impossível dogmatizar sobre a linguagem, podemos compará-la a uma "imagem gramatical" cujas propriedades podemos dominar. Construímos, por assim dizer um caso ideal sem a pretensão que este corresponda seja ao que for, mas apenas a fim de obter uma visão sinóptica, com a qual podemos comparar a linguagem; trata-se de um "aspecto" que não afirma nem nega nada. Na impossibilidade de garantir que conhecemos todas as regras gramaticais relativas a uma palavra, não podemos afirmar perentoriamente de que modo exacto ela deverá ser empregue; qualquer palavra pode ser empregue de muitas maneiras diferentes ${ }^{3}$.

Ao referir a crítica de Frege à ideia de que a aritmética é um simples jogo de signos, Wittgenstein suspende qualquer resposta definitiva, deixando a questão de lado. Não afirma nem nega que a aritmética seja um jogo de signos, adopta simplesmente outro ponto de vista. "Sejamos justos e não afirmemos nada, deixemos, antes que as coisas falem elas mesmas"4.

É notória a proximidade destes textos de alguns dos parágrafos das $I n$ vestigações Filosóficas, nomeadamente dos que têm como alvo a visão fregeana da linguagem e a exigência de termos predicativos e funcionais com contornos nítidos, isto é, que referem exactamente um conceito bem delimitado. Todos os conceitos e funções devem, segundo Frege estar sujeitos ao requisito segundo o qual, todo o objecto ou é ou não é subsumido por esse conceito ou função. Portanto, Frege rejeita qualquer tipo de vagueza ou oscilação de significado no emprego dos signos linguísticos. Todos devem ter uma referencia e só uma, não podem estar à mercê do uso que lhes é dado: ao contrário do que propõe Wittgenstein, abster-se de enunciar toda a afirmação definitiva sobre o significado de uma palavra, Frege contradizendo textualmente Wittgenstein considera que "é assim que se deve empregar esta palavra, é isso que constitui propriamente o seu sentido".

Nos parágrafos 70 e seguintes, Wittgenstein estabelece um diálogo silencioso com Frege, um diálogo silencioso porque a voz de Frege se faz ouvir através do interlocutor imaginário. E um diálogo deslocado, por assim dizer, porque as duas vozes não estão bem sintonizadas, isto é, não estão a falar da mesma coisa: não só porque a exigência de Frege é ditada pelo seu objectivo de construir uma linguagem lógica exacta, perfeita, sem lugar para vaguezas nem ambiguidades, enquanto Wittgenstein tem em mente a linguagem corrente na sua dimensão essencialmente práxica; mas também porque o que Frege entende por conceito é fundamentalmente diferente da noção de

\footnotetext{
3 Cf. ibid., 140-41.

4 Ibid.
} 
conceito de Wittgenstein. Para Frege, o conceito é o referente de um predicado gramatical, é um termo insaturado, e não é formado nem produzido pela mente humana; os conceitos, funções, relações são constitutivos da própria realidade e por isso são "apreendidos" (grasped) - é a melhor metáfora que Frege encontra para explicar como compreendemos um conceito. É algo de indizível, inexprimível, o acesso ao conceito dá-se através de uma apreensão intelectual, directa, não são fruto de nenhuma elaboração subjectiva, não se formam mentalmente. Os conceitos estão aí, já constituídos, e podem ser ou não ser apreendidos. A sua apreensão por parte de um sujeito não afecta para nada o próprio conceito em si. Eles mostram-se simplesmente.

Para Wittgenstein, os conceitos podem ser analisados através da aplicação das palavras; podem ser explicados, elucidados através de uma análise gramatical, que no entanto, deixa sempre em aberto a pergunta "O que é um conceito?" A formação do conceito não é ditada por nenhuma pressuposta essência da realidade. A gramática do nosso esquema conceptual é autónoma, pois na medida em que pode ser em parte configurada por constrições pragmáticas, não pode ser correcta ou incorreta num sentido metafísico ${ }^{5}$. Nesta passagem há nitidamente uma flutuação na formação do esquema conceptual, de tal modo que nos seria difícil compreender alguém que tivesse um esquema conceptual completamente diferente. Mas daí não se pode inferir qual o esquema correcto ou incorrecto.

Este desencontro nota-se nitidamente nos argumentos e exemplos com que Wittgenstein responde a Frege: a estratégia de Wittgenstein é mostrar com exemplos expressões de contornos vagos ou esfumados, ou esquemas conceptuais diferentes, que são recorrentemente utilizados na nossa linguagem comum sem originarem qualquer confusão ou ambiguidade. O terreno de Wittgenstein é o da prática e uso da linguagem no quotidiano.

Para Frege, o requisito de conceitos com contornos nítidos, da determinação do sentido constitui o verdadeiro critério para uma investigação; não é a contradição, como geralmente se pensa, que constitui o verdadeiro critério, pois um conceito contraditório será necessariamente vazio, isto é, nenhum objecto pode ser subsumido por um conceito contraditório; a verdadeira pedra de toque é a percepção das fronteiras, dos contornos que delimitam o

5 Cf. IF, II, xii, §2. "Eu não digo, no sentido de uma hipótese, que se os factos da natureza fossem de outra maneira, os homens teriam conceitos diferentes. O que eu digo é que uma pessoa que acredita que certos conceitos são absolutamente correctos e que quem tivesse outros não compreenderia o que nós compreendemos, então essa pessoa pode conceber certos factos da natureza de carácter muito geral de uma maneira diferente daquela a que estamos habituados; outras estruturas conceptuais ser-lhe-ão mais compreensíveis do que aquelas a que estamos habituados." Cf. Glock 2010. 
conceito ${ }^{6}$, todo o conceito não contraditório tem fronteiras nítidas, caso contrário não é um conceito. A referência a este requisito ocorre na obra de Frege desde a Begriffsschrift até aos escritos póstumos; Frege insiste reiteradamente na necessidade da total determinação do sentido dos conceitos e relações ${ }^{7}$. Todo o conceito e relação deve ter um valor para cada objecto, de contrário seria impossível formular leis lógicas sobre $\operatorname{conceitos}^{8}$. Este requisito é, para Frege, um ideal exigido pela linguagem lógica, pela analiticidade da aritmética e pela objectividade do sentido; a linguagem natural é imperfeita, não governada por leis lógicas e a mera gramática não garante a correcção formal dos processos de pensamento ${ }^{9}$. Nestes casos, a expressão das inferências é tão vaga, tão variada, tão livre que facilmente escapam pressupostos sem serem notados nem tidos em conta ao enumerar as necessárias condições para as conclusões correctas ${ }^{10}$.

O requisito de uma definição completa para os termos conceptuais "Uma definição de um conceito (de um possível predicado) deve ser completa; deve determinar sem ambiguidades, em relação a qualquer objecto, se este cai ou não sob o conceito" 11 - corresponde ao ideal de exactidão, determinação, contido na ideia de conteúdo conceptual, numa relação recíproca com o seu método, a ideia de análise. É convicção de Frege (e de Wittgenstein no Tractatus) que o termo da análise consiste na redução final às componentes primitivas de algo composto por natureza, com uma certa estrutura formal. A exigência de alcançar uma exactidão final, implica a compreensão da natureza destes signos primitivos, ou originários e dos objectos correspondentes a que se referem ${ }^{12}$. E no entanto, estes signos são realmente indizíveis.

A existência de objectos simples (dos quais Wittgenstein nunca conseguiu dar um exemplo) é um requisito lógico-transcendental, determinado pela exigência de uma análise completa, cujo termo fosse algo inanalisável.

6 "Contradictions were indeed a driving force behind the search, but not contradictions in the concept; for these always carry with them a sharp boundary: it is known that nothing falls under a contradictory concept [...] The real driving force is the perception of the blurred boundary. In our case too, all efforts have been directed at finding a sharp boundary." (KS, 123/CP, 134; itálicos nossos)

7 Cf. Bs, §27; Gg, vol. II, 76; Grl, §56; Tr, 33, 159, 170; PW, 155.

8 Cf. Tr, 33

9 "Language is not governed by logical laws in such a way that mere adherence to grammar would guarantee the formal correctness of thought processes. The forms in which inference is expressed is so varied, so loose and vague, that presuppositions can easily slip in unnoticed and then be overlooked when the necessary conditions for the conclusions are enumerated." $(\mathrm{CN}, 85)$

10 Cf. Frege 1964, 155.

11 Cf Gg, II, §56.

12 Cf. Holiday 2005, 39. 
A concepção da linguagem como reveladora do processo de pensamento, permitiria alcançar respostas finais. Os ideais de exactidão completa, através de uma análise exaustiva, nortearam o processo de análise da linguagem em Frege e em Wittgenstein (Tractatus), apesar das diferenças entre o primeiro e o segundo.

Em Frege, a objectividade do sentido e o seu realismo extremo, se por um lado permitem uma análise exacta da linguagem, por outro, levantam questões sem resposta: o que significa propriamente "apreender" os sentidos dos termos (nomes, predicados) que referem objectos individuais ou conceitos? Como se garante a objectividade dos sentidos se estes são a via, a mediação entre o signo (empregue pelo locutor) e a referência? Os sentidos dos termos não estão determinados ou condicionados pela compreensão e pelo uso do sujeito que os emprega? E assim, o sentido não terá também uma dimensão ou uma vertente subjectiva?

Além disso, os limites do que pode ser expresso por meio da linguagem, impostos por Frege, não permitem definições de alguns dos elementos importantes do sistema. São propriedades dos pensamentos e das relações estruturais e lógicas entre conteúdos conceptuais que constituem a base da perspectiva logicista de Frege e não podem ser apreendidos nem pela linguagem nem pelo pensamento. São necessariamente inexprimíveis e indefiníveis termos como "o Verdadeiro", "conceito", "objecto". Não podem ser representados no simbolismo, mas mostrados pela função que nele desempenham Veja-se por exemplo a discussão de Frege com Kerry sobre "o conceito de cavalo" em "Conceito e Objecto"13.

Em Wittgenstein, no Tractatus, trata-se de um processo idealmente essencialista, que visa, através da análise lógica, esgotar todas as possíveis determinações de qualquer objecto. Esta determinação, em Wittgenstein, não procede de uma descoberta, de um ver claramente o que a coisa é, mas de uma selecção das propriedades que melhor se coadunam com o que teoricamente postulamos ser essencial. Precisamente por ser essencialista, preside a todo o processo de análise a ideia de um fim, um termo. A análise tem de ser completa, não deixa nada de fora. Mas o essencialismo é aqui mitigado pela selecção das propriedades que melhor se articulam com a essência postulada. No Tractatus o essencialismo não é mais do que um requisito da lógica, que garante a possibilidade de análise completa, postulando a existência de objectos simples.

13 Cf. "On Concept and Object", Tr, 42-55. Aqui Frege, tal como Wittgenstein (Tractatus), considera que o que não pode ser dito em lógica, mas se mostra nela são precisamente as suas noções fundamentais: conceito, juízo, função, constantes lógicas. Cf. Geach 1976. 
Nas Investigações Filosóficas, Wittgenstein corta pela raiz este ideal de alcançar uma análise final das nossas formas de linguagem e de alcançar uma exactidão total após uma análise exaustiva ${ }^{14}$. Não temos nunca essa clarividência, ou melhor, aspirar a essa clarividência é um logro que nos induz a pensar que há algo oculto, para lá das expressões que empregamos correntemente. O que se pretende não é uma visão exacta, mas uma compreensão que progressivamente se vai constituindo através da observação do uso, de explicitações e elucidações. Estas não têm como meta alcançar um termo final de plena compreensão. Não há termo final, trata-se de um processo continuado, progressivo. Por isso as perguntas da forma "O que é?" são ilusórias, porque pretendem ou pressupõem uma resposta final de uma vez por todas, que não resulta da experiência, nem do uso, mas é totalmente independente. Não há um termo final, uma visão totalmente definitiva, ou qualquer coisa como uma definição. Não há nada oculto para além das nossas expressões correntes; elas são o que são, o uso é que lhes dá vida. As nossas formas usuais de expressão não carecem de uma análise, como se nelas houvesse algo oculto que fosse trazido à luz no termo desse trabalho de análise.

O essencialismo ideal de outrora, transforma-se num anti-essencialismo realista, colado ao uso e à praxis linguística do dia-a-dia. Nos Ditados a Waismann, Wittgenstein rejeitara a pergunta socrática pelas definições: "Não posso caracterizar melhor o meu ponto de partida do que declará-lo totalmente oposto ao que Sócrates representa nos diálogos platónicos"15. Note-se, no entanto, que além desta diferença - a recusa de perguntas da forma "O que é?" - Wittgenstein transpõe as questões socráticas da metafísica para o plano linguístico. A resposta à pergunta "O que é X?" não é dada através da inspecção de essências ou naturezas, mas através da elucidação do significado de "X", determinada pelas regras do uso de X - "A essência manifesta-se na Gramática"16. A análise de um conceito não é senão a apli-

14 Cf. IF, §91: "Mas agora pode criar-se a aparência de que existe uma análise terminal das nossas formas linguísticas e, portanto, uma forma perfeitamente decomposta da expressão. Como se as nossas formas habituais de expressão estivessem essencialmente por analisar; como se nelas existisse algo oculto que devesse ser trazido à luz e que, uma vez isto feito, a nossa expressão fica perfeitamente esclarecida e o nosso trabalho resolvido. | Dito de outra maneira: uma possível má-compreensão é eliminada ao tornarmos a nossa expressão mais exata; mas pode parecer que aspiramos a um determinado estado de exatidão perfeita; como se isso fosse de facto a meta da nossa investigação" (itálico nosso).

15 D, 17: e neste texto há já uma referencia a Frege, na qual Wittgenstein rejeita a delimitação nítida dos conceitos: “[...] se compararmos, como fez Frege, o conceito com um domínio recortado num plano, então, o que poderíamos dizer, é que o uso do dito conceito corresponde a um domínio com limites esfumados."

$16 \mathrm{IF}, \S 371$. 
cação de uma palavra ${ }^{17}$. $\mathrm{O}$ erro de Sócrates na procura de uma resposta à pergunta, por exemplo "O que é a virtude?" é o facto de rejeitar explicações parciais, explicitações por exemplificações e analogias ${ }^{18}$. Uma resposta assim precisa, determinada, restrita, é uma fixação do olhar e da atenção num ponto único, desatendendo as múltiplas e variadas relações que isso mesmo tem com tudo o resto e sobretudo com as variantes que vai ganhando com o uso. É de facto uma inspecção, mas não uma circunspecção; no primeiro caso ficamos com um significado fixo isolado, sem vida; no segundo atendemos a toda a vida, à vasta gama de significações possíveis que enriquecem e completam o primeiro significado. De certa forma, o essencialismo ou a pretensão de alcançar "o que é...", passa a uma forma de anti-essencialismo idealmente essencialista, isto é, o protelar a resposta definitiva e final, não significa uma rendição, uma forma de reconhecimento de um fracasso. Não, pelo contrário, o que se exige nesta nova investigação "gramatical" é um esforço continuado, uma tensão mantida na busca de uma compreensão mais ampla, "paisagística".

Por isso, na maior parte dos contextos, Wittgenstein propõe que uma pergunta Socrática seja substituída por outra. Recusa dar uma resposta precipitada, que seria sempre parcial, limitada. A pergunta " $O$ que é $X$ ?" não deve pretender uma resposta dada através de uma visão da natureza ou da essência (objectos mentais ou abstractos), mas uma resposta baseada na elucidação do significado de "X", que por sua vez é determinado pelas regras do uso de " $X$ "19. Como já foi dito, a proposta de Wittgenstein é a de que uma pergunta de estilo socrática como "O que é X?" deverá ser substituída por outra, "O que significa $X$ ?", que por sua vez deverá ser transferida para "Como é empregue ou usado X?". Wittgenstein sintetiza este desvio da primeira para a segunda e desta para a terceira pergunta no seu conhecido slogan "Não pergunte pelo significado, pergunte pelo uso." A pergunta pelo significado de uma palavra induz-nos no erro de pressupor algum objecto para além do signo, e configura um conceito de significação totalmente inadequado. Perguntas como "O que é o sentido?", "O que é o cumprimento?" produzem em nós uma "cãibra mental", na expressão de Wittgenstein ${ }^{20}$.

17 Cf. ibid., $\$ 383$

18 Cf. Glock 2010, 93.

19 Cf. IF, $\S \S 371,383$.

$20 \mathrm{Cf}$. BB, 1: O BB abre exatamente com estas perguntas perturbadoras porque nos induzem a pensar que deveríamos apontar para alguma coisa ao responder, mas não conseguimos apontar para nada. 
Como alternativa, para saber "o que é o sentido", temos que perguntar o que é "uma explicação do sentido" 21 . Se o sentido de "sentido" é "a explicação do sentido", esta explicação tem como correlato a compreensão, isto é o que compreendemos quando compreendemos "o sentido" e as suas explicações ${ }^{22}$. Há, portanto uma conexão entre sentido, explicação e compreensão. O que não é fácil de decidir é se a "explicação do sentido" pressupõe já a sua compreensão, ou se esta resulta da explicação. Se, como pensam Baker e Hacker, a explicação é o correlato da compreensão e vice-versa, então teremos que considerá-las como duas vertentes de um mesmo processo, isto é, o explicar, o elucidar vão a par e passo com a compreensão. Por isso Dummett considera que "as questões filosóficas sobre a significação encontram uma melhor interpretação como questões sobre a compreensão: dizer em que consiste o significado de uma expressão, deve ser uma tese sobre o que é conhecer o seu significado"23.

Esta perspectiva sobre o significado remete-nos, assim para a compreensão dos conceitos. Se uma teoria do significado deve ser uma teoria da compreensão, assim também uma teoria sobre os conceitos deve ser uma teoria sobre o que é possuir um conceito. A natureza do conceito não é senão a correcta explicação da capacidade que tem um pensador de compreender esse conceito e assumir atitudes proposicionais em relação a conteúdos nos quais ocorra esse conceito.

Estamos portanto perante dois processos paralelos - do significado para a compreensão, pela via da explicação, e dos conceitos para a posse (ou, segundo a expressão de Frege, a apreensão) dos conceitos. O que é a explicação? O que é compreensão? Apesar de serem correlativos, segundo a interpretação de Baker e Hacker, podemos compreender uma proposição ou um termo conceptual, sem determos uma explicação exaustiva. Como se processa a compreensão? Vejamos como Wittgenstein entende este processo de explicação e compreensão.

\section{Sentido, explicação, compreensão}

Antes de mais, Wittgenstein propõe-se, através de uma investigação gramatical eliminar uma má compreensão, resultante de certas analogias en-

${ }^{21}$ Cf. BB, 1-2; IF, §560: "O sentido da palavra é aquilo que a explicação do sentido explica".

22 Cf. Baker e Hacker 2005, 29: "Meaning is what is explained in giving an explanation of meaning. It is the correlate of understanding; and understanding is the correlate of explanation."

23 Dummett 1996, 35. 
tre formas de expressão em domínios diferentes. Nestes casos, é necessário afastar as confusões e mal entendidos resultantes de semelhanças aparentes entre formas de expressão que pertencem a diferentes "jogos" e têm as suas regras próprias. Um exemplo bem conhecido deste caso é o da semelhança ilusória entre as expressões "Eu tenho um livro" e "Eu tenho uma dor"; a análise gramatical mostra a profunda diferença entre estas duas expressões e serve para elucidar a noção de "dor".

Através da "análise" da expressão, que consiste em substituir uma forma de expressão por outra e por outra, é possível uma aproximação paulatina do sentido da expressão. Trata-se de uma "análise gramatical", um processo que se assemelha por vezes a uma decomposição. ${ }^{24}$ Mas, Wittgenstein esclarece de imediato, esta análise não é uma análise exaustiva, terminal, que alcance "uma forma perfeitamente decomposta da expressão". O que se pretende é uma elucidação que vai progredindo através de variações, como se fossem variações musicais, de uma forma de expressão: tal como na música podemos empregá-la e ouvi-la num tom que não é o mais apropriado, e temos então que tentar outros tons até atingir um que satisfaça mais. Mas este um não significa que alcançamos então a forma perfeita, final. Nem é isso que se pretende: as variações podem prosseguir indefinidamente e encontrar formas de expressão mais ou menos apropriadas.

Wittgenstein afirma expressamente:

[...] uma má compreensão é eliminada ao tornarmos a nossa expressão mais exacta: mas pode parecer que aspiramos a um determinado estado de exactidão perfeita; como se isso fosse de facto a meta da nossa investigação. (IF, §91; itálico nosso)

A exactidão total é inatingível, não por incapacidade das nossas explicações e exemplos, mas porque isso significaria o fim, o termo da investigação, por outras palavras, fixar o significado desse termo conceptual e fechá-lo portanto a outras explicações e exemplos futuros que fossem iluminando o seu significado, mostrando novas possíveis aplicações ou usos desse termo.

O diálogo imaginário entre Frege e Wittgenstein referido acima (IF, $\S \S 70$ e 71) exemplifica bem as suas diferentes posições em relação à exacta determinação de sentido de um termo conceptual ou de como alcançar um "estado de exactidão perfeita", na expressão de Wittgenstein. Discute-se a dificuldade de considerar o "jogo" como um conceito, tendo em conta a variedade de determinações de jogos totalmente diferentes. Perante tais dificuldades, ouve-se a voz de Frege: "Mas se o conceito de jogo é assim ili-

${ }^{24}$ Cf. IF, §90. 
mitado, então também tu não sabes o que queres dizer com jogo". Resposta de Wittgenstein: "Quando eu faço a descrição: 'O chão estava todo coberto de plantas' queres tu dizer que eu não sei de que falo, antes de poder dar uma definição das plantas?"

Como é notório, a estratégia argumentativa de Wittgenstein não consiste em responder directamente aos argumentos, mas o de mostrar com exemplos casos práticos de expressões que podemos compreender, mesmo que os conceitos não estejam totalmente explicados e definidos. Poderíamos dizer aqui que o uso, a prática, a compreensão implícita da expressão supre a necessidade de definições completas e exaustivas. Não saberíamos dizer exactamente o que é uma planta, mas isso não impede a compreensão da frase. Isto significa que no uso da linguagem empregamos muitos termos cuja definição última (se esta existir) ignoramos, não a saberíamos pôr por palavras. Mas a compreensão do todo não é afectada por essa aparente falha ${ }^{25}$.

O texto acima referido descreve implicitamente toda a problemática da necessidade/ou não de exigir uma total determinação e fixação do significado de um termo conceptual. "O que é o jogo?", pergunta de estilo socrático, à qual Wittgenstein evita dar uma resposta exacta, mas substitui por outra pergunta, e outra, e outra. As perguntas sucedem-se e constituem a forma da explicação. Não há uma resposta final, uma definição. Mas não se pode dizer que não compreendemos o que é um jogo.

Pelo contrário, Frege reitera constantemente que todo o conceito deve ter um valor para todo o objecto, de contrário seria impossível formular as leis lógicas sobre conceitos. Isto é, um "conceito" que não tenha fronteiras nítidas e determinadas, não é um conceito ${ }^{26}$. Por isso no referido diálogo, Frege conclui que se o conceito de jogo é tão ilimitado, não sabemos o que queremos dizer com jogo. O mesmo é dizer que não se trata de um conceito, não obedece às leis lógicas de um conceito. Frege expulsaria este predicado vago "ser um jogo" da sua linguagem formal.

"Poder-se-ia dizer que o conceito de jogo é um conceito de contornos esfumados." Diria Frege: - "Mas um conceito esfumado seria de todo um conceito?"27 Não cumpriria o requisito de nítida determinação, logo não seria um conceito. A estratégia de Frege, como veremos em próximos exemplos, é a de excluir todos os termos conceptuais que não satisfaçam o requisito da precisa delimitação. Na maior parte das suas observações, Frege exprime uma perspectiva puramente negativa da vagueza. Interessa-lhe sobretudo evitar termos vagos na sua linguagem formal e para isso emprega sempre o

\footnotetext{
25 Não cabe neste ensaio explorar mais exaustivamente a noção de compreensão.

26 Cf. por exemplo Tr,.33, 139 ss., PW, 152 ss., 195 ss., 229 ss., 241, 243 ss.

$27 \mathrm{IF}, \S 71$.
} 
seu critério de delimitação precisa e nítida, sem apresentar qualquer teoria da vagueza ou de uma linguagem vaga ${ }^{28}$.

Tomando à letra o requisito de contornos nítidos, Wittgenstein cita a comparação fregeana do conceito a uma área: "uma área sem fronteiras precisas não se pode de todo chamar uma área" 29 . De facto, Frege faz essa comparação ${ }^{30}$. Mas, em primeiro lugar, Frege está a recorrer a uma metáfora e o exemplo refere-se a representações de conceitos em extensão, por áreas num plano e acrescenta imediatamente que esta imagem deve ser tomada com precaução. $\mathrm{O}$ exemplo serve para ilustrar o que seria considerar uma área sem contornos definidos; não seria uma área, tal como um conceito sem contornos definidos não seria um conceito. Mas note-se que Frege está aqui a considerar as extensões dos conceitos; os conceitos não se identificam com as suas extensões ${ }^{31}$. A comparação que Frege faz com uma área diz respeito ao conceito extensionalmente considerado, ou seja aos objectos por ele subsumidos. Se não fora assim o exemplo da área estaria completamente deslocado, uma vez que os conceitos não se identificam nem com a sua extensão (embora a determinem), nem com os objectos por ele subsumidos. Frege nunca define conceito, apenas indica que é o referente de um predicado gramatical, mas apressa-se a esclarecer que o conceito não se identifica com a extensão nem com a classe. Portanto um conceito refere-se realmente "ao

28 Cf Ruffino 2003. Van Heijenoort (1986, 31-45) apresenta vários exemplos da mera rejeição de qualquer forma de vagueza, argumentando simplesmente que nesses casos não se trata de termos conceituais. Veja-se por exemplo, logo na Begriffschrift, o Teorema 81, $\$ 27$, que não vou apresentar aqui, implicaria que um único feijão ou mesmo nenhum, seria sempre um montão de feijões. Para ultrapassar a dificuldade, Frege defende simplesmente que o predicado em causa é "indeterminado", o que induz a proposições indeterminadas (unbeurtheilbare). Com estas notas Frege coloca os predicados vagos fora dos limites da lógica. O mesmo exemplo é referido em carta a Peano de 29 de Setembro de 1896: a falácia conhecida pelo nome de "Acervus" assenta no facto de termos como "montão" ser tratado como se designassem um conceito claramente delimitado, quando de facto não é o caso.

29 IF, §71.

30 Cf. Gg, II, §56

31 Cf. Couto-Soares 2001, 78: "Um conceito pode ser extensionalmente considerado quando a sua extensão é quantificável, isto é, quando se pode dizer quantos e quais os objetos subsumidos por esse conceito (...)“. No entanto, Frege sublinha a distinção nítida entre conceito e extensão. Cf. KS, 210: “A extensão de um conceito não consiste nos objetos que caem sob esse conceito, assim, como, por exemplo, um bosque consiste nas suas árvores; está ligado ao conceito e só a ele. Mas o conceito precede a sua própria extensão." (itálico nosso) “. Contra a ideia de identificar a classe ou extensão com a própria referência do conceito, Frege esclarece num escrito póstumo: "Poder-se-ia facilmente chegar ao ponto de tomar a extensão conceptual como a referência do termo conceptual; com isto, porém, não seria levado em conta que extensões conceituais são objetos e não conceitos" (NS, 129). 
que é ser F", ou se quisermos à propriedade ou características que definem "F".

Uma das consequências da clara distinção entre conceito e objecto (classes, etc.) é o seguinte paradoxo para o qual Frege não dá uma saída: a admissibilidade de um conceito é totalmente independente da questão de saber se este subsume objectos, e se for o caso, que objectos subsume. Para responder a estas questões, temos já que ter o conceito. Entre conceito e objectos por ele subsumidos, dá-se um processo circular, que Frege não pode evitar: a única maneira de mostrar que um conceito tem uma determinada propriedade é indicar um objecto que caia sob esse conceito; mas para isso é necessário ter já o conceito ${ }^{32}$. Por outras palavras, Frege parece querer admitir que é possível a compreensão, o saber o que é independentemente de saber dizê-lo, contraste que está em causa em Wittgenstein.

Assim, o citado paradoxo de Frege - a necessidade de ter já o conceito para saber se um objecto é ou não subsumido por este, e por outro lado a total independência do facto de um conceito subsumir ou não objectos - pode ser traduzido na inconsistência expressa nas Investigações Filosóficas:

O que é que quer dizer saber o que é um jogo? O que é que quer dizer sabê-lo e não ser capaz de o dizer? É este saber de algum modo equivalente a uma definição sem palavras, de tal maneira que ao ser posta em palavras eu a posso reconhecer como a expressão do meu saber?” (§75)

O que significa uma "definição sem palavras"? Uma certa compreensão ou pré-compreensão que não encontra ainda uma forma de expressão? Por um lado, Wittgenstein rejeita a identificação entre compreender "jogo" com a capacidade de dizer (definir) o que é um jogo. O pressuposto do $§ 75$ é precisamente a distinção entre compreender e ser capaz de dizer, definir, por outras palavras, a compreensão de uma pessoa transcende o que ela é capaz de dizer como resposta à pergunta "O que é um jogo?". O facto de se ser incapaz de definir, não significa que não se seja capaz de compreender.

O que está em causa é a distinção entre saber e ser capaz de dizer.

$32 \mathrm{PW}, 179$ " $[. .$.$] the only requirement to be made of a concept is that it should$ have sharp boundaries: that is, that for every object it holds that it either falls under the concept or does not so. [...] But the admissibility of a concept is entirely independent of the question whether objects fall under it, and if so which, or in other words; whether there be objects, and if so which, of which it can be truly asserted. For, before we can raise such questions, we already need the concept. [...] The only apparent way to show a concept has this property is to cite an object falling under the concept. But to do that you already need the concept." 
Esta mesma distinção é reformulada no contraste entre explicação e definição; a definição é o que pressupõe o saber, as explicações poderão conduzir à definição, à compreensão do que é um "jogo": "Não é o meu saber, o meu conceito de jogo completamente expresso nas explicações que eu possa dar?"33 Isto é o conjunto de explicações e exemplos poderão tornar-se equivalentes a essa "definição sem palavras", ou conduzir à compreensão, ao saber?

Baker e Hacker explicitam esta relação entre explicação, exemplos e definições: quem compreende o que é um jogo a partir de explicações e exemplos, deve empregar estes modelos de uma maneira particular, para o usar correctamente. Portanto, parece que a sua compreensão vai para além dos exemplos, incorporando também uma apreensão de como empregá-lo. E isto não se pode pôr por palavras na explicação. Sendo assim, se as explicações através de exemplos são a única via de explicar "o jogo", parece óbvio que o que se explica é apenas uma parte do que se compreende. Parece que sabemos o que é um jogo mas não o conseguimos dizer (explicar) ${ }^{34}$.

O símile com o referido paradoxo de Frege pode ser expresso do seguinte modo: para saber se um objecto cai ou não sob um conceito, preciso já de ter esse conceito; no entanto, esse conceito é independente da questão do ou dos objectos que possa subsumir, e pode mesmo não subsumir nenhum objecto. Daí que seja possível "ter" conceitos, isto é saber o que é isto, mesmo sem saber se isso existe ou não, e antes de saber se isso pertence ou não a esse conceito. Na formulação de Wittgenstein seria possível saber de algum modo o que é isto numa espécie de "definição sem palavras", independentemente de ser capaz de dizer. As explicações, recorrendo a exemplos, analogias, são formas de dizer que elucidam e aproximam-se da definição. Mas nunca terminam numa definição única e exacta.

$\mathrm{Na}$ linguagem corrente, lidamos constantemente com termos cujos significados não são exatos, e a sua delimitação é imperfeita, variável: não sabemos qual o significado de um termo se não compreendermos o seu contexto, a situação em que é utilizado; o modo como é empregue, a própria tonalidade, a voz, introduzem cambiantes no significado do termo. Muitos predicados são vagos, pois não conseguimos decidir para cada objecto se esse predicado the pode ser aplicado. Enfim a flutuação de sentido, a ambiguidade, a amplidão do sentido de um termo, fazem parte da vida da linguagem corrente. Não constituem propriamente defeitos ou falhas no uso correcto, mas essa correcção total é impossível, pela impossibilidade de estabelecer regras exaustivas para o uso de todos os termos. As palavras, os adjectivos, os verbos, as frases idiomáticas, etc. escapam a essa rigidez precisamente

\footnotetext{
$33 \mathrm{IF}, \S 75$.

34 Baker e Hacker 1980, 386.
} 
porque têm uma vida própria, estão sujeitas ao passar do tempo, às mudanças de circunstâncias culturais, sociais.

Esse carácter vago da linguagem corrente é tolerado por Frege. Considera-o como uma deficiência inultrapassável, ou até mesmo uma característica típica de uma linguagem que não aspira à pureza e ao rigor formal, e que por isso mesmo não tem relevância para a sua construção de uma linguagem lógica, formalmente precisa e determinada. Para Wittgenstein, ele é mesmo constitutivo da própria linguagem, não como uma falha, uma deficiência, mas como a marca da nossa linguagem, dos nossos jogos, que encontram diversos modos de alcançarem os seus fins, os seus objectivos, a partir de um mínimo de regras que os constituem. Ir para além das regras é mesmo o grande segredo do "jogo", ir para além das regras é sinal de um domínio (nunca completo) do uso da linguagem.

\section{Referências}

Baker, G. P., e P. M. S. Hacker. 1980. Wittgenstein: Understanding and Meaning, vol. I. Chicago: The University of Chicago Press.

-----. 2005. Wittgenstein: Understanding and Meaning, vol. I - Exegesis $\S \S 1-184$, second, extensively revised edition by P. M. S. Hacker. Oxford: Blackwell.

Couto Soares, M. L. 2001. Conceito e Sentido em Frege. Porto: Campo das Letras.

Dummett, M. 1996. The Seas of Language. Oxford: Clarendon Press.

Frege, G. 1967 (1879). Begriffschrift, a formal language, modeled upon that of arithmetic, for pure thought, in From Frege to Gödel: A sourcebook in mathematical logic (1879-1931), ed. J. Van Heijenoort. Cambridge, MA: Harvard University Press. (Bs)

------. 1884. Die Grundlagen der Arithmetik, eine logisch-mathematische Untersuchung über den Begriff der Zahl; 1992. Os Fundamentos da Aritmética, trad. A. Zilhão. Lisboa: INCM. (Grl)

-----. 1893, 1903. Grundgesetze der Arithmetik, begriffsschriftlich abgeleitet, 2 vols. Hildesheim: Georg Olms. (Gg)

-----. 1964 (1882). "On the Scientific Justification of a Conceptual Notation", Mind 73 (290), 155-60.

-----. 1967. Kleine Schriften, ed. I. Angelelli: Hildesheim: Georg Olms. (KS)

-----. 1971. Nachgelassene Schriften, eds. H. Hermes, F. Kambartel e F. Kaubach. Hamburg: Felix Meiner (NS); 1979. Posthumous Writings, trad. P. Long e R. White. Oxford: Basil Blackwell. (PW)

-----. 1972. Conceptual Notation and related articles, trad. T. W. Bynum. Oxford: Clarendon Press. (CN) 
1980. Translations from the Philosophical Writings of Gottlob Frege, 3rd ed., trad. P. Geach e M. Black. Oxford: Basil Blackwell. (Tr)

-----. 1984. Collected Papers on Mathematics, Logic, and Philosophy, ed. B. McGuinness. Oxford: Blackwell. (CP)

Glock, H.-J. 2010. "Wittgenstein on Concepts", in Wittgenstein's Philosophical Investigations: A critical guide, ed. A. Ahmed. Cambridge: Cambridge University Press.

Heijenoort, J. Van. 1986. "Frege and Vagueness" in Frege Synthesized, eds. L. Haaparanda e J. Hintikka. Dordrecht: D. Reidel Publishing Company. Geach, P. 1976. "Saying and Showing in Frege and Wittgenstein", in Essays on Wittgenstein in honor of G. H. von Wright, ed. J. Hintikka. Amsterdam: Rodopi.

Holiday, D. A. 2005. "Determinacy of sense" in Frege and Wittgenstein. Philosophy MSc. The University of Edinburg (www.era.lib.ed.ac.uk)

Kemp, G. 1996. "Frege's Sharpness Requirement", The Philosophical Quarterly, 46, 183: 168-84.

Ruffino, M. 2003. "Frege's Views on Vagueness", Manuscrito, 26, 2: 253-77 .

Wittgenstein, L. 1958. The Blue and Brown Books, ed. R. Rhees. Oxford: Blackwell. (BB)

-----. 1987. Investigações Filosóficas, in Tratado Lógico-Filosófico e Investigações Filosóficas, trad. M. S. Lourenço. Lisboa: Fundação Calouste Gulbenkian, Lisboa (IF)

1997. Dictées de Wittgenstein à Waismann et pour Schlick. Textes inédits années 1930, ed. A. Soulez. Paris: PUF. (D) 